\title{
Screening Method Research on Main Water Polluters of Liao River in Liaoyang
}

\author{
Xiang $\mathrm{He}^{1, \mathrm{a}}$,Fan Wang $^{1}$, Runlei Cai ${ }^{1}$, Xuejiao Feng ${ }^{1}$ \\ ${ }^{1}$ School of Municipal and Environmental Engineering, Shenyang Jianzhu University, \\ Shenyang,110168, China \\ aemail:syjzhexiang@163.com
}

Keywords: water polluters; equal standard pollution load; analytic hierarchy process; controlling totalquantity

\begin{abstract}
The water polluters of Liao river in Liaoyang is elected preliminarily basing on the basin of the key water polluters of Liaoyang city, combining with the principle of polluters screening and the computing method of equal standard pollution load, optimizing and assessing the indexes which involves the discharge of waste water, the discharge destination of waste water,the pollution discharge of COD and the pollution discharge of $\mathrm{NH}_{3}-\mathrm{N}$ etc. Then the primary results are further elected with the method of hierarchy analysis basing on the standard layer indexes which involves the result of equal standard pollution load , the discharge destination of waste water ,the industry category ,the discharge method of waste water and the level of pollution source management. Finally, the rankings are compared and the final selection list is confirmed.This method provides technical support of the control of both the concentration and total quantity of the water pollution source, and the implementation of monitoring of total pollutant quantity.
\end{abstract}

\section{Introduction}

The Liao River basin (Liao River water system and Large Liao River water system) is one of the major 7 basins in China. The Liao River is total 1,390km long[1]. The Liao River basin section in Liaoning province mainly covers the aggregated industrial parks and intensive downtown with mature economic development. After several decades of development, it concentrates the core industries such as petrol chemical industry, metallurgic industry and equipment manufacturing industry, and it currently is the critical industry raw material producing area and the equipment manufacturing base in domestic[2]. As a result, the Liao River basin in Liaoning province is facing the severe water pollution problems and the comprehensive pollution index ranks the top position in 7 major basins in China for long time. The offshore pollution problem in Liaoyang is very severe and the functional zones can hardly meet the standard requirements[3].

In light of the main problems in monitoring and management of water environment in Liao River basin and also the scientific and technologic demands of "The 12-fifth Plan", and according to the natural conditions and water quality \& geologic features of Liao River basin, establish the technical method system of monitoring system for total quantity of water pollutants which comply with the features[4]. Since the screening of pollution resources is the basis of this technical system, the reasonable screening is helpful to enhance the representativeness of complete system data. However, most of the traditional screening methods adopts the equal standard pollution load method[5]. The shortage of this method is that it only considers the effect of pollution discharge amount on the pollution, but neglect the effect of industry category and economic conditions. So this article, based on the traditional screening method, adopts the AHP widely used for pollutant evaluation to re-order the screening results so as to reject the pollution sources with less comprehensive effect and then obtain the final screening results [6]. This method can make up the shortage of single consideration factor with the traditional method so as to enable more representativeness of screening results and more adequate expression of pollutant features. 


\section{Pollution sources screening principle}

According to national regulations, the monitored object for total amount is mainly the major pollution sources in the basin, including the major industry pollution sources, large scale livestock and poultry farms or aquiculture areas and the urban sewage treatment plants. The basic screening principles are as follows Wen Huang[7] said.

The preparation of above 5 principles refers to Statics Method for Total Amount Reduction of Major Pollutants in "12-fifth Plan"[8]. In addition, on the basis of national regulated principles, the Liaoning province also issued relevant documents. The Monitoring Program of Pollution Sources in Liaoning Province in 2012 regulates: "Except the nationally key monitored waste water pollution sources and the pollution sources directly discharged to the sea, the enterprise with daily waste water discharged of more than 100 tons or chemical oxygen demand of more than $10 \mathrm{~kg}$, the chemical enterprise directly discharging into the river "and also the enterprise which may impost safety hazard on local environment by the discharged toxic and hazardous substances are included in the monitoring range.

\section{Pollution sources screening method}

According to the basic principle for screening of above monitored objects, in combination with the factors such as environment management demand, total amount distribution program, water environment function areas difference and actual monitoring capability, fulfill the local adjustment and conduct the multi-mode screening for pollution sources of Liao River in Liaoyang; Take the union set for the screening results.

\section{Pollution source primary screening method}

Primarily select the comprehensive pollution sources screening principal and equal standard pollution load calculation method, and take the union set for all principles; it can fulfill the primary screening. The primary screening consists of four steps:

The first step screening: according to principle (1), screen all pollution sources in Liao River in Liaoyang with the equal standard pollution load metods[9]; and obtain the major pollution sources list with large equal standard pollution loads;

Equal standard pollution load (pollutant) = pollutant discharge amount (in t/a) / environment quality standard limit value (in mg/L) (water).

The calculation formula is as follow:

The equal standard pollution load value (pollution source) is the sum of equal standard pollution load of each pollutant discharged by this pollution source. The total equal standard pollution load value of certain system is the sum of equal standard pollution load of each pollution source generated in this system. Carry out the equal standard pollution load analysis for the pollution discharge enterprises in Liao River; the determination of discharge limit (Coi, evaluation criteria of pollutant) refers to Environment Quality Standards for Surface Water (GB3838-2002).

Step 2: according to the major monitoring principles in Liaoning province and national principle (3), screen the direct discharge waste water enterprise in residual pollution sources and then obtain total 697 direct discharge pollution sources;

Step 3: According to principle (2), screen the discharge waste water amount for residual pollution sources after the screening in pervious two steps, and then obtain 315 pollution sources with the "daily waste water discharge amount of no less than 100 tons".

Step 4: According to the chemical oxygen demand (COD) discharge principle in Liaoning province, screen the residual pollution sources from previous screening steps with COD method, and then obtain 256 pollution sources with the "daily COD discharge amount of no less than 10kg". Complete above 4 screening steps and conclude the 4 lists screened out, i.e.: taking the union set for the pollution sources screened out with equal standard pollution load principle and the pollution sources in direct charge sources with "daily waste water discharge amount of no less than 100 tons" \& "daily COD discharge amount of no less than $10 \mathrm{~kg}$ ". The sorted list is the primary list of 
pollution sources which shall be monitored in emphasis in the target basin, totaling 274 sources.

Total 171 major pollution sources are screened out in Liao river in Liaoyang, in which there are 94 pollution enterprises with the accumulated equal standard pollution load accounting for $85 \%$ of total equal standard pollution load. In these 94 pollution sources, there are 28 pollution enterprises with direct discharge mode, of which the daily industry waste water discharge amount is no less than $100 \mathrm{~T}$ and the daily COD discharge amount is no less than $10 \mathrm{~kg}$. In the direct discharge pollution sources, there are 22 pollution enterprises with the daily industry waste water discharge amount of no less than 100 tons and the daily COD discharge amount of no less than $10 \mathrm{~kg}$.

\section{Pollution sources precise screening process}

Considered the amount of pollution sources in the screening results are still large, this program further handles the screening results to screen out the major pollution enterprises in major pollution industries as the pollution sources list for precise screening. The precise screening process adopts AHP. The AHP ranks the 94 pollution sources in the primary screening list and conducts matrix calculation with YAAHP software[10].

1.Establishment of AHP model

This study considers the integral pollution impact of pollution sources on the basin as object layer A, the equal standard pollution load B1, industry category B2, pollution discharge path B3, pollution source level B4 and the discharge mode B5 as the rule layer B, and the pollution sources as program layer C.

2.Construct the judgment matrix

The AHP structure chart can clearly show out the affiliation relationship between elements of all layers; it can construct the two-by-two judgment matrix at different layers according to the rule layer of previous class. If the two-by-two judgment matrix is taken as (Cij) nxn, then $\mathrm{Cij}>0$, $\mathrm{Cij}=1 / \mathrm{Cij}, \mathrm{Cii}=1(\mathrm{I}, \mathrm{j}=1,2, \ldots \mathrm{n})$ (n: number of element). Since the elements governed by object layer A and rule layer B is fixed relative to the complete decision system, the weight relative to the rule will also keep constant[11].

The two-by-two comparison and judgment matrixes for decision layer to rule layer B-5 are separately as (B1-C), (B2-C), (B3-C), (B4-C) and (B5-C); the matrix is indicated as:

$\mathrm{YC}=(\mathrm{Cij}) \mathrm{n} \times \mathrm{n}$

Construction method of (Cij) nxn: assign the index value of certain item of the ith industry pollution source as xi, then:

(1) If all $X_{i}$ are larger than 0 , assign $C i j=x i / x$;

(2) If any $X_{i}$ is less or equal to 0 , assign $C i j=a x i-x j$

Compare each index in pollution source (C1-n) with rule layer (B1-5) in pairs and construct 5 $\mathrm{n} \times \mathrm{n}$ order judgment matrixes.

From related correlation theorem of matrix eigenvalue, above constructed n-order positive and negative judgment matrix have the positive feature root and the corresponding positive feature vector. Normalize the feature vector corresponding to the maximum feature root, and the relative weight of the element of this layer to certain element in previous layer can be presented with the feature vector obtained by normalization. Such process is called as single hierarchical arrangement.

3.Determination of valuation rules

From the run program of AHP, we need establish corresponding index system based on the evaluated object features and natures, and then determine the multi-layered evaluation structure model according to the index system. Establish the waste water pollution sources evaluation index system with above steps:

(1) Expert consultation method

Select different classes of environment protection professional technical and management personnel; make use two methods of symposium and expert consultation to get awareness of their understanding for the comprehensive evaluation of pollution sources and understand their awareness for the influencing factors on the waste water pollution sources pollution degree in detail, and then conduct statistics analysis for the consulted results. Select 5 indexes in offered various influencing factors as the indexes for AHP rule layer, mainly including: pollution source 
management level, waste water discharge path, pollution source industry type, waste water discharge mode and pollutant discharge amount. Then conduct the investigation and analysis in form of questionnaire survey and finally determine the relative significance weight value of each index and the parameter valuation range of each rule. At last, conclude and obtain the relative significance weight value and valuation standard of each rule.

(2) Entropy weight method

The entropy weight method is a extremely objective weight assignment method. During actual operation, the entropy weight method can base on the variation degree of each index and make use of the information entropy to calculate the entropy of this index, and then correct the weight of each index with entropy weight so as to figure out the relatively objective indicator weight[12]:

(1) Determine the final weigh of each index from the significance of comprehensive index and the information amount provided by the index.

(2) Based on the 94 items to be evaluated and 5 evaluation indexes from primary screening, from the original data matrix, in which Rij is the evaluation value of the ith item under the jth index.

$$
R=\left(\begin{array}{cccc}
r_{11} & r_{12} & \ldots & r_{1 n} \\
r_{21} & r_{22} & \ldots & r_{2 n} \\
\ldots & \ldots & \ldots & \ldots \\
r_{m 1} & r_{m 2} & r_{m 3} & r_{m 4}
\end{array}\right)_{m \times n}
$$

(3) The valuation process of weight of each index value is as follow:

(1) Calculate the weight of index value of the ith item under the jth index $p_{i j}$ :

$p_{i j}=r_{i j} / \sum_{i=1}^{m} r_{i j}$

(2) Calculate the entropy of the jth index $e_{j}$ :

$e_{j}=-k \sum_{i=1}^{m} p_{i j} \cdot \ln p_{i j}$

$k=1 / \ln m$

(3) Calculate the entropy of the jth index $w_{j}$ :

$w_{j}=\left(1-e_{j}\right) / \sum_{j=1}^{n}\left(1-e_{j}\right)$

(4) Determine the index comprehensive weight $\beta_{j}$ :

The evaluator can determine the weights for the importance of index according to own purposes and requirements. Assumed the index significances separately as $j=1,2, \ldots, n$, and combined the entropy weight of indexes, figure out the comprehensive weight of index $\mathrm{J}$ :

$$
\beta_{j}=\frac{\alpha_{i} w_{i}}{\sum_{i=1}^{m} \alpha_{i} w_{i}}
$$

(4)With above steps, conduct the significance assignment for 274 items and 5 indexes to be evaluated in Liao River in Liaoyang. According to the formula in step 3, the final weight values of 5 indexes are calculated.

Determine the valuing rule for the hierarchy structure model in this study with entropy weight method and the results are calculated.

According to the valuing rule obtained with entropy weight method, set up the judgment matrix of rule layer $\mathrm{B}$ for target layer $\mathrm{A}$ as follows:

By calculation: the maximum feature $\operatorname{root} \lambda \max =4$ and the corresponding feature vector $\mathrm{WB}-\mathrm{A}=$ $(0.400,0.267,0.133, .0 .133,0.200)$; use the same method and format two-by-two judgment matrixes of C-B1, C-B2, C-B3, C-B4 and C-B5. The calculated maximum feature roots of above matrixes are separately as $\lambda \max 1=43, \lambda \max 2=43.5588, \lambda \max 3=43, \lambda \max 4=43$ and $\lambda \max 5=46.3991$. Determine the feature vector corresponding to the maximum feature value of above matrix and substitute in the formula to obtain the weight vector $\mathrm{W}$ of target layer. The results are shown in the 
table 1.

Table 1 Relative weights of sources

\begin{tabular}{cccccccccc}
\hline NO & weight & NO & weight & NO & weight & NO & weight & NO & weight \\
\hline 1 & 0.0663 & 6 & 0.0558 & 11 & 0.0403 & 16 & 0.0468 & 21 & 0.032 \\
2 & 0.0615 & 7 & 0.0491 & 12 & 0.0524 & 17 & 0.038 & 22 & 0.032 \\
3 & 0.0663 & 8 & 0.0347 & 13 & 0.0327 & 18 & 0.0468 & & \\
4 & 0.0642 & 9 & 0.0347 & 14 & 0.0343 & 19 & 0.038 & & \\
5 & 0.0578 & 10 & 0.0463 & 15 & 0.038 & 20 & 0.032 & & \\
\hline
\end{tabular}

(4) Consistency test of matrix consistency:

Define and judge the consistency proportion of matrix

$\mathrm{CR}=\mathrm{CI} / \mathrm{RI}$

$\mathrm{CI}=($ Kmax-n)

$/ \mathrm{n}$

(7)

CI - Consistency index of two judgment matrixes;

Where: Kmax: Maximum feature root; $n$ : order of judgment matrix; RI: average and random consistency index degree. In case of $\mathrm{CR}=\mathrm{CI} / \mathrm{RI}<0.1$, it can be judged that the consistency of judgment matrix can be accepted; otherwise the index degree of judgment matrix shall be properly corrected and adjusted. The combination ordering is by layers from top to bottom and the results shall be subject to general consistency check. In case of $\mathrm{C} . \mathrm{R}(\mathrm{K})<0.1$, it can be considered all judgments of above $\mathrm{K}$ layer have complete and satisfactory consistency. Carry out consistency check for A-B matrix, if $C I=(K m a x-n) /(n-1)=(5-5) /(5-4)=0, C R=0$, it meets the consistency requirements; adopt the same method to conduct consistency check for B1-C, B2-C, B3-C, B4-C, $\mathrm{B} 5-\mathrm{C}$, the resulted consistency proportions are separately of $0,0.0078,0.0078,0,0.0474$; use it in $\mathrm{CR}(\mathrm{k})$ calculation formula and obtain $\mathrm{CR}(\mathrm{k})<0.1$, and it meets the consistency requirement. At this point, the ordering of pollution sources completes.

\section{Test Results}

Rank the relative weights of all pollution sources in descending order. By calculation, the sum of relative weights of first 12 pollution sources in ranking is more than $65 \%$ of total value. The pollution sources in the demonstrative zones shall be monitored as major sources; take the results as the precise screening results. At this point, the pollution sources screening works complete and the list is shown in the table 2.

Table 2 List of target sources

\begin{tabular}{|c|c|c|c|c|c|}
\hline $\mathrm{NO}$ & Reporting company name & weight & NO & Reporting company name & weight \\
\hline & Petro & & & & \\
\hline 1 & $\begin{array}{c}\text { China Liaoyang Petrochemical } \\
\text { Company }\end{array}$ & 0.0663 & 7 & Dengtan Zhenguo Paper Mill & 0.0524 \\
\hline 2 & $\begin{array}{l}\text { Liaoyang Tianhua Cotton Printing } \\
\text { and DyeingLimited Company }\end{array}$ & 0.0663 & 8 & $\begin{array}{l}\text { Liaoyang Fuli Synthetic } \\
\text { Chemical Plastics Factory }\end{array}$ & 0.0491 \\
\hline 3 & $\begin{array}{c}\text { Liaoyang Renhe Printing and } \\
\text { Dyeing Mill }\end{array}$ & 0.0642 & 9 & $\begin{array}{c}\text { Liaoyang Huayi Printing and } \\
\text { Dyeing Mill }\end{array}$ & 0.0468 \\
\hline 4 & $\begin{array}{l}\text { Liaoyang ShunhangPaper } \\
\text { Industry Limited Company }\end{array}$ & 0.0615 & 10 & $\begin{array}{l}\text { Liaoyang Mingbang Printing } \\
\text { and Dyeing Limited Company } \\
\text { Anshan Iron and Steel Group }\end{array}$ & 0.0468 \\
\hline 5 & $\begin{array}{l}\text { Liaoning Qingyang Special } \\
\text { Chemicals Limited Company }\end{array}$ & 0.0578 & 11 & $\begin{array}{l}\text { Mining Company of Gong } \\
\text { Changling Mining } \\
\text { CompanyDressing Plant }\end{array}$ & 0.0463 \\
\hline 6 & $\begin{array}{c}\text { Liaoyang Sanlian DyeingLimited } \\
\text { Company }\end{array}$ & 0.0558 & 12 & $\begin{array}{c}\text { Liaoning Dacheng Agriculture } \\
\text { and Animal Husbandry Industry } \\
\text { Limited Company Liaoyang } \\
\text { Branch }\end{array}$ & 0.0403 \\
\hline
\end{tabular}




\section{Conclusion}

(1) In combination of the equal standard pollution method of traditional pollution sources with AHP, conduct primary and precise screening for the water pollution sources in Liao river in Liaoyang, and effectively avoid the situation in which the screening results only consider the pollution discharge amount, but neglect other factors.

(2) It has important reference value for the monitoring point arrangement for the basins at startup phase of entire monitoring system such as Liao River in Liaoyang. In long basin, the collection requirements for large amount of information reduce the working amount of monitoring personnel and also enhance the work efficiency. According to the ranking of precise results, it can install online monitoring equipment by batch for Liao River in Liaoyang. For the pollution sources with high pollution and severe impact, firstly check the installation of monitoring devices. It can enhance the economic performance of monitoring system and also ensure the representativeness of monitoring data.

(3) Through the coupled application of equal standard pollution load method and the AHP, it determines 12 layout monitoring enterprise for the first batch in whole Liao river in Liaoyang, and also provides strong technical support for the concentration control, total amount control and also the pollutant total amount monitoring.

\section{Acknowledgement}

In this paper, the research was sponsored by the China Enviromental Protection Foundation of “123 Project”(Project No. CEPF2012-123-2-3) and Main Pollutant Emission Control and Management System Construction of Liao River Basin(Project No. 2012ZX07505-002-002).

\section{References}

[1] Zhao Lulu.Assessment of Aquatic Ecosystem Function of Liao River Basin and Identification of the Major Factors[D].Liaoning University,2011.

[2] Zhang Mingyu,Li Kai.Building and Practice of Urban Agglomeraiton in Central Liaoning under Regional Innovation Perspective[J].Liaoning Urban and Rural Environmental Science \& Technology,2007,7(3):143-146.

[3] Li Rui.Integration and Optimization of Evaluation Method for Treatment Technology of Typical Papermaking Wastewater at Liao River Basin[D].Northeaster University,2010

[4] General Office of the State Council of the People's Republic of China.Ci-rcular of the State Council Issued on the Plan of Energy-saving and Emission-reduction[Z].2007-5-23.

[5] Y.Panagopoulos,C.Makropoulos,M.Mimikou. Decision support for diffuse pol-lution manag ement[J].Environmental Modelling \& Software.2012,11(30):57-70.

[6] Zhang Lixin.Application of Analytic Hierarchy Process (ahp) in the River Monitoring Se ction Optimization[J].Liaoning Urban and Rural Environment Science\&Teachnology,2007, 5(1):45-47.

[7] Puyang Ri Water Environment Impact Assessment of Pujiang County, Zhejiang Province Polluters Based on Standard Pollution Load Method[J].Water Science and Technology,2014,5(8):74-75.

[8] General Office of the State Council of the People's Republic of China. General office of the state council on forwarding of environmental protection "twelfth five-year" main pollutant total emission reduction assessment measures.2013-1-5.

[9] Han Long,Jin Xiao,et al.Analysis of Equal Standard Pollution Load on Industrial Wastewater in Shenzhen[J].Science Environment,2013,32(6):25-32.

[10] Fadim Yavuz,Tüzin Baycanb.Use of Swot and Analytic Hierarchy Process Integration as a Participatory Decision Making Tool in Watershed Management [J].Procedia Technology,2013,11(8):134-143.

[11] Badea,F.\&G.Prostean.Assessing Risk Factors in Collaborative Supply Chain with the A 
nalytic Hierarchy Process (AHP)[J].Procedia - Social and Behavioral Sciences,2014,124 (20):114-123.

[12] Chen Lei,Wang Yanzhang.Research on TOPSOS Integrated Evaluation and Decision Me thod Based on Entropy Coefficient[J].Control and Decision,2003,18 (4) : 456-459. 